\title{
Prevalence of glaucoma in the west of Ireland
}

\author{
Michele Coffey, Angela Reidy, Richard Wormald, Wu Xing Xian, Lesley Wright, \\ Parul Courtney
}

Western Health Board,
Ireland
M Coffey

\section{Public Health}

Department, Barnet

DHA, Colindale

Hospital, London

A Reidy

Western Ophthalmic Hospital and St Mary's

Hospital Medical School,

Eondon

$\mathrm{R}$ Wormald

L Wright

\section{Institute of}

Ophthalmology, London

W X Xian

P Courtney Health Department, Colindale Hospital, Colindale Avenue, London NW9 5HG.

Accepted for publication 17 August 1992
Correspondence to:

Dr Angela Reidy, The Public

\begin{abstract}
County Roscommon in the west of Ireland is a relatively remote rural area whose population of 55000 is served by two community medical ophthalmologists and three optometrists. Eye surgical services are not available within the county. In order to assess the needs of the community for prevention of blindness from glaucoma, a simple random sample of the population of County Roscommon was taken for a community based glaucoma survey. A total of 2186 people over the age of 50 were examined which represented a $99.5 \%$ response rate. The high response rate was achieved by the community basis of the study and vigorous follow up of non-attenders. Intraocular pressure was measured using applanation tonometry, disc evaluation by both direct ophthalmoscopy and stereoscopic biomicroscopy, and visual field analysis using the Henson CFS 2000 and experimental computer controlled video perimetry. Diagnostic criteria were consistent with the preferred practice pattern of the American Academy of Ophthalmology. A crude prevalence of approximately $\mathbf{2 \%}$ for primary open angle and normal tension glaucoma was found. The population profile of intraocular pressure showed a pattern which decreased with increasing age unlike the Framingham and Ferndale studies but similar to Japanese data.

(BrF Ophthalmol 1993; 77: 17-21)
\end{abstract}

Glaucoma is a major cause of irreversible

Figure 1 Co Roscommon.

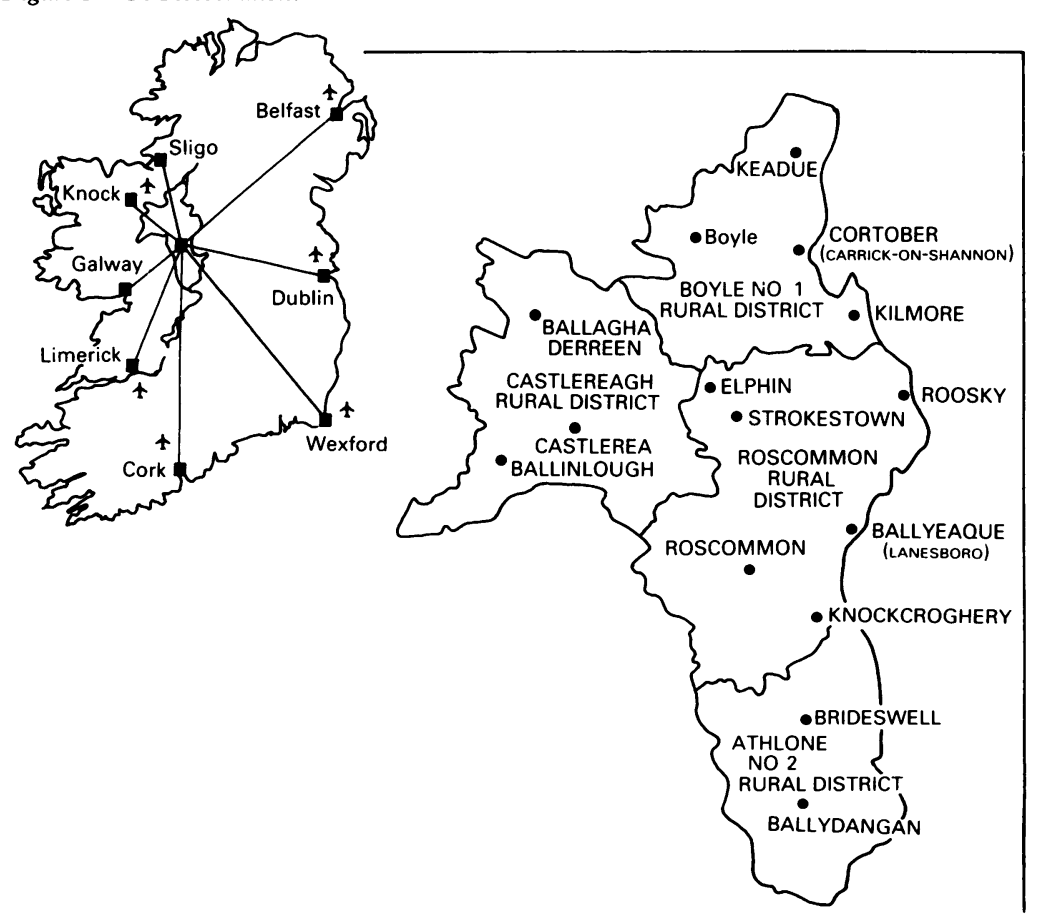

blindness throughout the world and is usually in the top three in industrialised nations. ${ }^{1}$ Most ophthalmologists believe that progressive loss of visual field can be arrested or at least slowed by effective lowering of intraocular pressure (IOP). Prevalence estimates of the disease from surveys are few. The most frequently quoted in the developed world are the Framingham study ${ }^{2}$ and the Ferndale study. ${ }^{3}$ Although both these surveys were population based, they were not true random samples of the population at risk. Recently, the results of the Baltimore eye study ${ }^{4}$ have been published in which glaucoma prevalence was carefully estimated in randomly sampled urban clusters of blacks and whites.

A belief is widely held that the prevalence of glaucoma is high in Ireland compared with other western countries. This is based on hospital based experience by Irish ophthalmologists and no population based figures from Ireland are available for confirmation or refutation of this impression.

The Ran-Sam method of sampling of electoral register of the republic of Ireland offered a unique opportunity to take a simple random sample of the population of County Roscommon. This mainly rural county is situated on the western bank of the Shannon in the middle of the country (Fig 1). The total population at the outset of the study was about 55000, with approximately 17250 over the age of 49 years.

The principal investigator of this survey (MC) holds one of two government appointments as community ophthalmologist to the county. The purpose of the study was to establish baseline estimates of glaucoma prevalence and other common blinding conditions in order to improve the planning of primary eye health care services for the county which could then be extrapolated to the country as a whole and similar communities elsewhere. It was planned during the 1.988 Diploma of Community Eye Health course at the International Centre for Eye Health and executed over the subsequent 2 years. The design, execution, and analysis of this project was supervised by an ophthalmologist with specialist training in epidemiology $(\mathrm{RW})$.

\section{Method}

\section{SAMPLE}

A simple random sample of the population of Co Roscommon was provided by Professor Brendan Whelan of the Economic and Social Research Institute(Dublin). This is a computerised sample from the electoral register using the Ran-Sam programme. Lists of names and addresses were provided which were a random sample of all individuals on the register. Ages were verified 
Figure 2 Age distribution by sex.

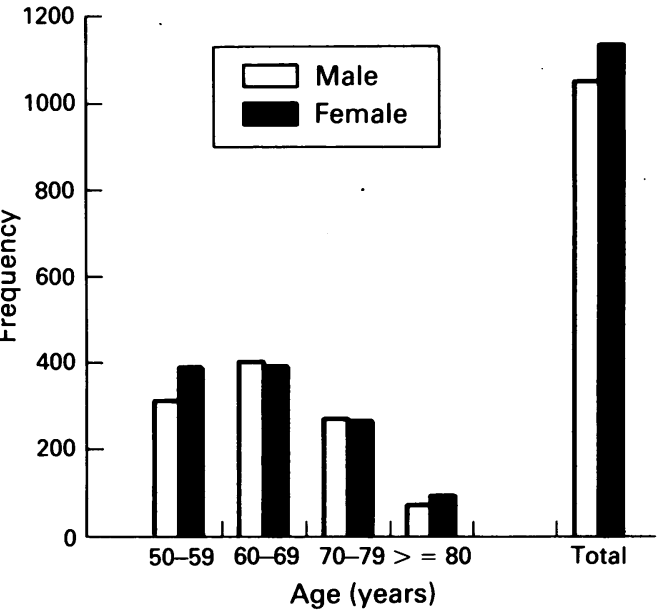

first through the use of local health board records and were further sorted by health board personnel so that a list of persons aged 50 and over eligible for the glaucoma survey was constructed. Individuals in the sample who were found to have died were replaced. People who were found to be too young on initial interview were examined but not included in the analysis as

Table 1 Prevalence of primary open angle glaucoma (including normal tension) (by age and sex with $95 \%$ confidence limits)

\begin{tabular}{lcclll}
\hline Age group & & No of cases & Sample & Prevalence $(\%)$ & $95 \%$ CL $(\%)$ \\
\hline Total & $50-59$ & 5 & 697 & $0 \cdot 72$ & $0 \cdot 09-1 \cdot 25$ \\
Males & & 2 & 309 & $0 \cdot 65$ & $0 \cdot 08-2 \cdot 3$ \\
Females & & 3 & 388 & $0 \cdot 77$ & $0 \cdot 16-2 \cdot 24$ \\
Total & $60-69$ & 14 & 794 & $1 \cdot 76$ & $0 \cdot 97-2 \cdot 94$ \\
Males & & 7 & 402 & $1 \cdot 74$ & $0 \cdot 7-3 \cdot 56$ \\
Females & & 7 & 392 & $1 \cdot 79$ & $0 \cdot 73-3 \cdot 64$ \\
Total & $70-79$ & 17 & 531 & $3 \cdot 2$ & $1 \cdot 87-5 \cdot 00$ \\
Males & & 10 & 269 & $3 \cdot 72$ & $1 \cdot 8-6 \cdot 73$ \\
Females & & 7 & 262 & $2 \cdot 67$ & $1 \cdot 08-5 \cdot 43$ \\
Total & $80+$ & 5 & 164 & $3 \cdot 05$ & $0 \cdot 995-6.98$ \\
Males & & 2 & 71 & $2 \cdot 82$ & $3 \cdot 48-9 \cdot 81$ \\
Females & & 3 & 93 & $3 \cdot 23$ & $0 \cdot 66-9 \cdot 14$ \\
\hline
\end{tabular}

Table 2 Prevalence (\%) of glaucoma by type, ocular hypertensives, and glaucoma suspects

\begin{tabular}{lrll}
\hline Diagnosis & No of cases & Sample & Prevalence $(95 \%$ CI) \\
\hline POAG: & 41 & 2186 & $1 \cdot 88(1 \cdot 35-2 \cdot 53)$ \\
CAG $^{b}$ & 2 & 2186 & $0 \cdot 009(0 \cdot 006-0 \cdot 3)$ \\
Secondary & 9 & 2186 & $0 \cdot 41(0 \cdot 19-0 \cdot 77)$ \\
Suspect & 23 & 2186 & $1 \cdot 05(0 \cdot 66-1 \cdot 57)$ \\
$\begin{array}{l}\text { Ocular } \\
\text { hypertensive }\end{array}$ & 65 & 1799 & $3 \cdot 61(2 \cdot 8-4 \cdot 58)$ \\
\hline
\end{tabular}

-Primary open angle glaucoma; 'Chronic angle closure glaucoma 'Includes only those participants who had Goldmann applanation readings in both eyes.

Table 3 Clinical features of glaucoma cases in the Roscommon glaucoma survey

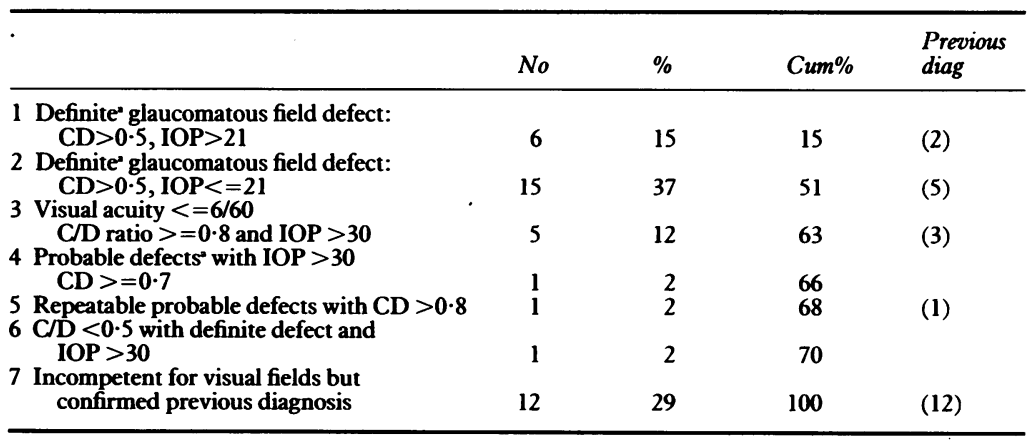

'Defects were graded as 'definite' when at least two quadrants were involved and the typical arcuate shape was observed. 'Probable' defects were smaller but the Henson automated assessment was abnormal with a 'field survival' of $<\mathbf{9 5 \%}$. were voluntary attenders. Following a local publicity campaign, participants were invited to attend by letter, and in many cases also by personal contact by public health nurses and general practitioners. Those who failed to attend after the first invitation were sent further appointments and, when necessary, were examined at home.

Sample size calculations indicated that 2200 persons needed to be examined in order to achieve a $95 \%$ probability of detecting a prevalence of glaucoma of $3 \%$ with $95 \%$ confidence limits of plus or minus $0.5 \%$.

\section{SURVEY CLINICS}

\section{Sites}

Well over 50 clinics were held throughout the county at 18 different sites. Where possible established health centres were used but, for easier access for people from rural areas, clinics were set up in community centres outside of the main towns. Those who could not attend at any of these sites were visited in their own homes.

\section{Procedures}

On arrival participants were registered on production of a letter of invitation and eligibility for inclusion in the survey established by the participants' stated age. Details of past ophthalmic history and relevant family history were recorded.

Examination procedures were as follows:

(a) Best corrected visual acuity using 6 metre Snellen chart.

(b) Applanation tonometry by Goldmann tonometer or Perkins Mk2 hand-held applanation tonometry.

(c) Assessment of anterior chamber angle by slit-lamp biomicroscopy using the van Herick method $^{5}$ and gonioscopy using the Goldmann single mirror when the angle appeared to be less than one half the peripheral corneal thickness.

(d) Cup/disc ratio estimation using slit-lamp biomicroscopy and the 90 dioptre fundus lens. Participants' pupils were dilated when an adequate view could not be achieved otherwise. Note was made of any other pathology detected in the anterior or posterior segment during this part of the examination. Interobserver variability studies between the ophthalmologists in disc assessment achieved a weighted kappa statistic for agreement consistently over 0.75 (denoting excellent agreement).

(e) Visual fields. Central visual field analysis using the Henson CFS 2000 semi-automated perimeter ${ }^{6}$ was performed on both eyes of initially one in 10 and subsequently all participants using the 132 point test. All glaucoma suspects (CD ratio $>0.5$ in one or both eyes), ocular hypertensives, and cases were tested unless incompetent to perform the test owing to poor vision or inability to understand the test. A total of $55.8 \%$ of the sample had their visual fields tested.

(h) Diagnostic conclusion and disposal. All cases of newly diagnosed of glaucoma, all new suspects and all ocular hypertensives were reviewed by a second ophthalmologist to confirm 
the diagnosis and gonioscopy was performed if not yet carried out. Arrangements for follow up were made locally.

Most participants also underwent Schiotz tonometry and direct ophthalmoscopy as part of a training exercise for the community health nurses. Data from these findings are not presented in this paper.

\section{Personnel}

The survey was conducted by ophthalmologists assisted by paramedical technicians and public health nurses who are normally employed by the Western Health Board. Standardisation of procedures was supervised by the ophthalmologist with epidemiological expertise (RW).

Visual acuity was tested by the public health nurses. Visual field testing was conducted by paramedical persons under the supervision of a teaching grade orthoptist and an ophthalmologist who specialises in visual field research (XW). The remainder of the examination of every participant was conducted by an ophthalmologist including estimation of cup/disc ratio.

\section{DATA MANAGEMENT STATISTICAL ANALYSIS}

Clinical data were entered on to a standard proforma and subsequently entered into a dedicated data base in SPSS (Statistical Package for Social Sciences) on an IBM compatible microcomputer.

Because the number of non attenders was so small, prevalences were calculated using the total number of participants examined: $95 \%$ confidence limits for the prevalence estimates were calculated using an exact binomial method for small proportions and the normal approximation to the binomial for larger ones. (Confidence

Figure 3 Mean applanation pressures (Roscommon glaucoma survey).

Figure 4 Cumulative frequency distribution of vertical cup/disc ratio.
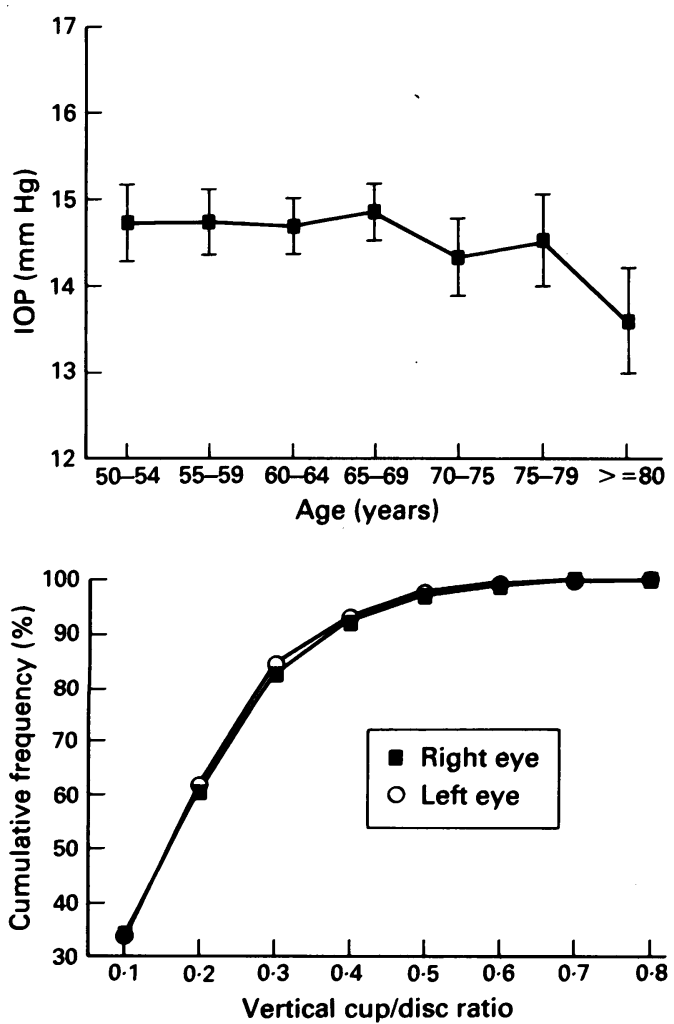

Interval Analysis software available from British Medical Association publications was used for this purpose.) Statistical associations in cross tabulations were assessed using the $\chi^{2}$ statistic.

\section{Results}

Of the 2200 individuals invited, 2186 participated making an attendance rate of $99.5 \%: 280$ were visited at home $(12 \cdot 8 \%)$ and $0.5 \%$ refused to be seen.

Figure 2 shows the distribution by age and sex of the population examined. There were slightly more females $(52 \%)$ than males $(48 \%)$. The age distribution of the sample which shows a marginally reduced proportion in the younger age group may reflect the population structure of the county which had considerable out migration in the 1950s. The age/sex distribution of the sample closely correlated with that of the population of the county as a whole.

The prevalence of primary open angle glaucoma (including normal tension glaucoma) in those persons aged 50 years and over was $1.87 \%$ ( $95 \%$ CI 1.3 to $2.5 \%)$. Table 1 shows the age specific prevalences for primary open angle glaucoma by gender with $95 \%$ confidence limits around each estimate. Table 2 gives the prevalence estimates for other glaucoma types, ocular hypertensives, and glaucoma suspects. A glaucoma suspect was defined as a person with raised IOP in one or both eyes $(>21 \mathrm{~mm} \mathrm{Hg})$ in the presence of a cup to disc ratio of $>0.5$ in at least one eye but with normal visual fields. An ocular hyperpertensive was defined as a person with raised IOP $(>21 \mathrm{~mm} \mathrm{Hg})$ in at least one eye with normal discs $(<0.55)$ and fields. Table 3 summarises the features of all the diagnosed primary open angle glaucoma cases.

Figure 3 shows the mean applanation IOP for left eyes for males and females by age group including ocular hypertensives but excluding glaucoma patients and suspects. Applanation IOP was normally distributed within each age and sex grouping.

Figure 4 gives the cumulative frequency distribution of vertical cup to disc ratio for left and right eyes separately. A total of $95 \%$ of the sample had a vertical $C D$ ratio of less than 0.5 and the median CD ratio was 0.2 for either eye. Glaucoma cases and suspects were excluded from this figure.

Fifty one percent of all POAG cases (including normal tension glaucoma) were previously diagnosed. The crude prevalence of known cases of POAG was $0.9 \%$ and that of newly detected cases was $0.9 \%$.

Pseudoexfoliation was detected at a prevalence of $1.33 \%$ (95\% CI $0.88-1.9 \%$ ). Nine out of 29 cases were unable to perform a visual field test because of poor acuity in one or both eyes (due to cataract in all cases). Out of the remaining 20 patients, seven (35\%) had glaucoma. However, because not all participants had their pupils dilated before being examined, the prevalence of pseudoexfoliation may be underestimated. Only cases with obvious changes at the pupillary margin and on the anterior lens capsule were diagnosed as pseudoexfoliation.

There were two cases of angle closure glaucoma 
Table 4 Age specific prevalences in the Baltimore eye study and the Roscommon study

\begin{tabular}{lllll}
\hline Age group & $\begin{array}{l}\text { BES } \\
P R E V\end{array}$ & $95 \% C I$ & $\begin{array}{l}\text { RGS } \\
P R E V\end{array}$ & $95 \% C I$ \\
\hline $50-59$ & 0.32 & $0.03-1.17$ & 0.72 & $0.13-1.31$ \\
$60-69$ & 0.77 & $0.31-1.57$ & 1.76 & $0.91-2.62$ \\
$70-79$ & 2.85 & $1.7-4.5$ & 3.20 & $1.81-4.59$ \\
$80+$ & 1.94 & $0.49-4.95$ & 3.05 & $0.54-5.55$ \\
\hline
\end{tabular}

and two cases of secondary glaucoma, one of which was thrombotic and the other aphakic. The remaining cases classified in Table 2 as secondary glaucoma were due to pseudoexfoliation (seven cases).

\section{BLINDNESS AND LOW VISION}

The prevalence of blindness $(<3 / 60)$ was $0.5 \%$ $(\mathrm{n}=12)$ for the whole sample ( 50 years and over). The prevalence of low vision $(<6 / 18)$ was $2.06 \%$ $(n=45) .13 \%(n=6)$ of persons with low vision and $25 \%(n=3)$ of the blind had glaucoma.

The prevalence of blindness amongst all glaucoma patients was $7 \cdot 3 \%$ and low vision, $14 \cdot 6 \%$.

\section{Discussion}

The high attendance rate was achieved because the survey was conducted in an agricultural community when most people are known to each other and, in particular, by the community nurses who were able to follow up non-attenders vigorously.

The prevalence of glaucoma is higher than some other population based glaucoma studies. Differences in prevalence estimates may arise because of different sampling methodology and different case definition. However, direct comparisons can be made to the estimates of glaucoma prevalence among the white population in the Baltimore Eye Study (BES). ${ }^{4}$ Their estimate for prevalence of glaucoma was $1 \cdot 3 \%$ for the white population sample in the same age bracket. The $95 \%$ confidence limits for the two study estimates do overlap so that the observed difference may be due to sampling error alone. Table 4 shows comparable age specific prevalence estimates for these two studies, none of which significantly differ.

Table 5 shows the results of other comparable glaucoma surveys carried out in western countries. There is remarkable concordance for the prevalence estimates from the three most recent surveys, namely Nottingham, BES and Roscommon and perhaps the use of more modern automated and semi-automated perimetry on a larger proportion of the samples has increased the detection rate. However, only two cases in

Table 5 Relative prevalences of glaucoma and ocular hypertension in comparable glaucoma surveys in western countries

\begin{tabular}{|c|c|c|c|c|c|}
\hline & $\begin{array}{l}\text { Ferndale } \\
\text { (Wales) }\end{array}$ & $\begin{array}{l}\text { Framingham } \\
\text { (USA) }\end{array}$ & $\begin{array}{l}\text { Dalby } \\
\text { (Sweden) }\end{array}$ & $\begin{array}{l}\text { Nottingham } \\
\text { (England) }\end{array}$ & $\begin{array}{l}\text { Roscommon } \\
\text { (Ireland) }\end{array}$ \\
\hline $\begin{array}{l}\text { Sample size } \\
\text { Age range } \\
\text { IOP upper limit } \\
\text { Sample type } \\
\text { Prevalence OH } \\
\text { POAG }\end{array}$ & $\begin{array}{l}4231 \\
40-74 \\
>20 \\
\text { Total } \\
9 \cdot 1 \% \\
0 \cdot 48 \%\end{array}$ & $\begin{array}{l}2631 \\
52-85 \\
>21 \\
\text { Total } \\
6 \cdot 9 \% \\
1 \cdot 4 \%\end{array}$ & $\begin{array}{l}1511 \\
55-70 \\
>30 \cdot 5 \\
\text { Total } \\
6 \cdot 95 \% \\
0 \cdot 85 \%\end{array}$ & $\begin{array}{l}874 \\
>49 \\
>22 \\
\text { GP list } \\
5 \cdot 1 \% \\
1 \cdot 7 \%\end{array}$ & $\begin{array}{l}2186 \\
>49 \\
>21 \\
\text { Random sample } \\
4 \cdot 2 \% \%^{\prime} \\
1 \cdot 87 \%\end{array}$ \\
\hline
\end{tabular}

${ }^{\lrcorner}$Includes ocular hypertensives and glaucoma suspects this survey had probable defects which might have been missed by less sensitive strategies. The Henson CFS 2000 is an instrument designed for screening purposes which maximises specificity at the cost of a lower sensitivity. Therefore, if anything, glaucoma prevalence may be underestimated with this strategy.

Another reason whereby glaucoma prevalence may be underestimated relates to our definition of glaucoma and the number of persons who had no visual field test performed. A total of 949 persons had no visual field test and all except 13 of these had a $C D$ ratio of $\leq 0 \cdot 5$. Eleven of these 13 were known cases of glaucoma whose vision was too poor to be able to perform reliable fields. The other two were seen in the community and failed to attend for field testing so that the diagnosis could not be refuted or confirmed. Of those who did have fields tested and whose greatest $C D$ ratio was $\leq 0.5$, there were 17 persons who had a relative or absololute arcuate scotoma, another 28 with paracentral scotomas, and 10 with hemifield defects. Because none of these had a pathological appearance of their optic discs, and in many cases other reasons could be found for the abnormality, in particular retinal vascular occlusions, these were excluded from the prevalence estimates. We now know that persons with small optic discs may get glaucomatous visual field defects without developing a pathological appearance to the disc until much later. One such patient was included with a definite field defect and a high IOP (Table 2). Two of the 17 with arcuate scotomas also had an IOP over $21 \mathrm{~mm} \mathrm{Hg}$ and were thus included as ocular hypertensives. If we were to include these cases and a similar proportion of those who did not have field tests (1.6\% of 949), the glaucoma prevalence estimate would rise by another 32 cases to $3 \cdot 7 \%$. Our published estimate is necessarily conservative and only includes cases that we had the resources to definitely confirm during the period of the survey.

Taking a cut-off at $>0.5$ for cup/disc ratio for glaucoma cases and suspects will tend to underestimate prevalence of glaucoma suspects. We had no category for normal tension glaucoma suspects in this study. The sample distribution of cup/disc ratio excluding glaucoma cases and suspects (Fig 5 ) shows that $2 \cdot 7 \%$ of the sample had $C D$ ratio of greater than $0 \cdot 5$. An unknown proportion of these may in fact be normal tension glaucoma suspects.

A striking feature of these results is the high proportion of 'normal tension' POAG detected during the survey. Ten newly diagnosed cases had IOP at $\leq 21 \mathrm{~mm} \mathrm{Hg}$ at survey while only six had raised pressure. This parallels Sommer's observations on the $\mathrm{BES}^{9}$ where only half the newly detected cases had raised IOP. This finding emphasises the poor performance of IOP as a screening test for glaucoma.

It is interesting that ocular hypertension is found to have a lower prevalence than might be expected. Whilst the ratio of age specific prevalence for glaucoma and ocular hypertension was $0 \cdot 72 \%$ to $4 \cdot 19 \%$ (1:6) for the $50-59$ year age group, the ratio is much less for the older age groups and the overall ratio $1: 3$. This might suggest that there is a shift with increasing 
age from large numbers of ocular hypertensives and few glaucoma patients in the younger age group to many more glaucoma sufferers relative to the number of ocular hypertensives in the older age groups and may reflect the natural history of disease in the untreated population.

Hospital based statistics will tend to be biased by referral practice and while IOP is relied upon by practitioners in the community to screen for glaucoma, a higher proportion of ocular hypertensives will be seen in the hospital eye service.

It is interesting to note that the prevalence of $\mathrm{OH}$ does not increase with age as has been previously reported by Armaly ${ }^{10}$ and the relationship between age specific prevalence of $\mathrm{OH}$ and POAG is similar to that described by Shiose ${ }^{11}$ in Japan. Of course, a one off measurement of IOP in a cross sectional survey may miss some ocular hypertensives who on repeated testing may regress to their mean IOP over $21 \mathrm{~mm} \mathrm{Hg}$. Similarly, a proportion of those classified as ocular hypertensives may regress to a mean below $22 \mathrm{~mm} \mathrm{Hg}$.

The frequency distribution of IOP which was normal in this sample also differs from the Ferndale study which showed a distribution skewed to the right.

As in many other published surveys, the proportion of previously undiagnosed glaucoma to previously diagnosed disease was $50 \%$. It is remarkable how consistent this figure is for studies conducted in Wales, Baltimore,
Barbados, and St Lucia and now the west of Ireland. The appointment of community ophthalmologists by the Western Health Board is one attempt to improve on this situation.

We thank The Western Health Board; the British Council for the Prevention of Blindness; the International Glaucoma Association the Irish Medical Research Council; the Leverhulme trust; Allergan (Ireland); Fisons; and Allen Foster, training consultant; Professor Gordon Johnson; Aldona MacBride, Director of Community Care; the team of public health nurses; Redmond O'Beirne and Frank Phelan, participating ophthalmologists; Kelly, Lauranne Kelly, Marie Kilgarrif and Michael Harkin, the Kelly, Lauranne Kelly, Marie

1 Foster A, Johnson GL. Magnitude and causes of blindness in the developing world. Int Ophthalmol 1990; 14: 135-40.

2 Leibowitz HM, Krueger DE, Maunder LR. The Framingham Eye Study. Surv Ophthalmol 1980; 24: (suppl) 335-610.

3 Hollows FC, Graham PA. Intra-ocular pressure glaucoma, and glaucoma suspects in a defined population. Br F Ophthalmol 1966; 50: $570-86$.

4 Teilsch J, Sommer A, Katz J, Royall R, Quigley H, Javitt J. Racial variations in the prevalence of primary open angle glaucoma. FAMA 1991; 226: 369-74.

5 Van Herick W, Shaffer RN, Schwartz A. Estimation of width of angle of anterior chamber. Am $\mathcal{F}$ Ophthalmol 1969; 68: $626-9$.

6 Vernon SA, Henry DJ, Cater L, Jones SJ. Screening for glaucoma in the community by non-ophthalmologically trained staff using semi automated equipment. Eye 1990; 4: 89-97.

7 Bengtsson B. The prevalence of glaucoma. $\mathrm{Br} \mathcal{F}$ Ophthalmol 1981; 65: 46-9.

8 Henson DB, Bryson H. Clinical results with the HensonHamblin CFS2000. In: Greve EL, Heyl A, eds. Seventh International Visual Field Symposium. Netherlands: W Junk, 1987: 233-8.

9 Sommer A, Tielsch JM, Katz J, Quigley HA, Gottsch JD, Javitt J, Singh K and the Baltimore Eye Survey Research Group. Relationship between intraocular pressure and primary open angle glaucoma among white and black Americans. Arch Ophthalmol 1991; 109: 1090-5.

10 Armaly MF. The Des Moines population study of glaucoma. Invest Ophthalmol 1962; 1: 618-28.

11 Shiose Y. Intraocular pressure: new perspectives. Surv Ophthalmol 1990; 34: 413-35. 